\title{
The Relationship between Supply Chain Strategies and Achievement of Competitive Advantage in seed Manufacturing Companies in Nairobi County, Kenya
}

\author{
Robert Arasa ${ }^{1}$, Rose Mwaura ${ }^{2}$, Tomas Ngui $^{3}$ \\ Graduate Business School, The Catholic University of Eastern Africa
}

\begin{abstract}
The concept of supply chain management is relatively a recent idea in agribusiness management literature. It has been postulated that supply chain strategies can result into efficiency and effectiveness which in turn leads to firms establishing a competitive edge over other firms. The study examines the influence of supply chain strategies (lean, agile and le agile) on achievement of competitive advantage in seed manufacturing companies.The study was carried out on twenty seed companies in Nairobi County, Kenya. Data was analyzed using both descriptive and inferential statistics. Correlation and analysis of variance (ANOVA) techniques were utilized. Findings indicate that the companies employed either of the supply chain strategies (lean, agile and le agile). Findings further reveal that the supply chain strategies do influence competitive advantage. The study concludes that supply chain strategies can influence competitive advantage if well executedbymanagers. The study recommends that managers of seed manufacturing firms need to take a keen interest not only in the formulation of good supply chain strategies but also effective execution of the same to achieve higher and sustainable competitive advantage.
\end{abstract}

Keywords: supply chain, strategies, competitive advantage, manufacturing firms, Kenya

\section{Introduction}

\section{Background of the Study}

The concept of supply chain management is relatively a recent idea in agribusiness management literature. Efficient agriculture supply chains can result from stable networks and common relations between input suppliers, producers, processors, traders and retailers. In recent years, crucial growth has been made in the development of new approaches for analyzing the arrangement and dynamics of agriculture supply chains and networks(Christopher, 2005).Similar to any other supply chain, the supply chain for agri-products is also a network of organizations involved in a number of processes and activities to meet the customer demands and satisfy them. Agrifood chains are complex systems involving multiple multifaceted firms usually working together within specific industry sectors (Bryceson\& Smith, 2008).Market globalization and steep competition are increasing the need for more efficient and effective strategies in meeting evolving market demands.

Customers are not only demanding products and services to be delivered at almost immediate availability, but their needs are constantly changing. This implies that manufacturing companies, due to their dependence on customers for the products they provide, now have to perform within a global market where competition is becoming more and more difficult and intense. Developing a competitive supply chain based on speed, flexibility, innovation, quality, and responsiveness in dealing with unpredictable market situations has become essential for most organizations. The target is to reduce cost through increase efficiency and effectiveness. These are key characteristics of agile and lean capabilities. While 'lean' focuses on efficiency of operations and cost savings, 'agility' focuses on flexibility and responsiveness of operations.

\section{Agribusiness industry in Kenya}

Agribusiness is a component of the manufacturing sector where value is added to agricultural raw materials through processing and handling operations. The private sector is largely responsible for the supply of seed, agrichemicals, farm machinery, and the supply of processing equipment and materials. Suppliers range from local agro-chemical stockiest, animal feed millers and small and medium sized enterprise (SME) agro-machinery fabricators, to large multinational companies involved in manufacturing, distribution and wholesaling. Agriculture is a major driver of Kenya's economic growth. Itscontribution to the country's GDP is around 25 percent, not countingindirect contributions through links with manufacturing, transportand communication, wholesale and retail and financial services. Agriculture is profoundly importantto nearly every one of Kenya's 41 million people. Around threequarters depend on the sector for their livelihood and survival,and around 90 percent of rural incomes come from agriculture((National Agribusiness Strategy Kenya, 2012). A rapidly changing and increasingly complex market environment, increasing globalization of agricultural markets presents agribusiness owners with complex challenges. Hence they must work around increasingly complex economic landscapes, which include growing specialization in distribution channels and logistics; rapidly changing and differentiated consumer preferences; and increasingly complicated norms, standards and technical specifications (National Agribusiness Strategy Kenya, 2012).

Kenya has a competitive geographical location. It is well placed as trade hub for East Africa, with ports and access to sea transport. Due to its wide and diverse climatic conditions 


\section{International Journal of Science and Research (IJSR) \\ ISSN (Online): 2319-7064}

Index Copernicus Value (2013): 6.14 | Impact Factor (2014): 5.611

the country is able to produce a wide selection of produce over an extended harvest time. For example Kenya is able to supply fresh mangoes to the market for 8 months of the year where India and Pakistan have only a three month harvest period. On the other hand, Mango exporters complain that $20 \%$ of the cost in exporting fresh mangoes is in the form of taxes; this is making them un-competitive in supplying the North African market (Ministry of Agriculture, 2010). The productivity of the agricultural sector is constrained by inefficiencies in the supply chain, resulting from limited storage capacity, lack of post-harvest services and poor access to input markets. These constraints in supply chaincould reduce Kenya's bargaining power and competitive advantage in local and global agricultural markets.

\section{Statement of the Problem}

Industries manufacturing products from agricultural resources are developing rapidly but complexities in supply chains of products often result in economically unviable cost structures. It seems that many companies in the agriculture related industries have started worrying about their current competitive positioning since profits of agricultural products are among the lowest (Xiao, Leung, Zhang\& Lai 2009). It is postulated that supply chains strategies lean, agile and leagile affects a firm's competitiveness in such areas as cost, working capital requirements, flexibility, service perception, and human resource among others.

Previous researchers have focused on various areas of supply chain other than its implications on firm competitiveness. For instance;Morash and Lynch (2002) studied global supply chain capability and performance andWu, Yeniyurt, Kim and Cavusgil (2005) studied the impact of IT on organizational supply chain capabilities.There has been little focus on research that relates supply chain strategies and competitive advantage in the agribusiness sector and in particular in Kenya. The sector includes multinationals and local companies where competition is quite intense. Hence the main objective of this study wasto investigate the relationship between supply chain strategies andachievement of competitive advantage in seed manufacturing companies in Nairobi County, Kenya.Thespecific objectives of this study were to; establish the supplychain strategies pursued by seed manufacturing firms,examine the influence of the employed supply chain strategiesonthe realization of firm's competitive advantage and establish the moderating effect of government policies on the perceived relationship between supply chain strategies and competitive advantage.

Understanding how supply chains strategies influence competitive advantage in agribusiness sector is useful to the stakeholders from the perspectives of increased awareness by managers regarding the usefulness of having supply chain strategies in enhancing business processes and creating competitive advantage and ultimately customers and the market benefittingfrom improved efficiency and effectiveness.

\section{Literature Review}

\section{Theoretical review}

This study is anchored on the various theories and views which are discussed hereto. These theories and views include; transaction cost theory,resource-based view, knowledge-based view, strategic choice theory and agency theory. It is argued that each of these concepts has application and some shortcomings indescribing the processes associated with various activities in supply chain management.In the last two decades, one of the most important debates that emerged in the field of strategic management is how firms achieve and sustain competitive advantage.

Thetransaction cost theory explains the vertical connection and integration of various elements of organizational supply chain from suppliers to customers. The focus of the firm is to minimize the sum of transaction costs and production costs. This theory, however, is criticized that it is primarily concerned with the direct economic factors in organizations and does not address some important aspects such as personal and human relations among other actors in the supply chain. The Resource Based View postulates that in order to achieve higher competitive advantage organizations pursue the acquisition of better economic resources. More attention has been paid to the application of resource-based view in organizational supply chain management during the past decade. Morash and Lynch (2002) employed resource based view in their study of global supply chain capability and performance applying the relational aspect of resourcebased view to "supply chain wide collaboration". is concerned with the economic aspect of operations in organizations. For competitive advantage the resource based view suggests that firms can earn sustainable super normal profits if they have superior resources and these resources should be Valuable, Rare, non-imitable and Non substitutable (Grant, 1991). The fundamental principle of the resource based view is that the basis for a competitive advantage of a firm lies primarily in the application of the bundle of valuable resources available at the firm's.Knowledge-based view these dimensions of organizational learning, evolutionary economics, organizational capabilities and competencies, and innovation and new product development. It is argued that for achieving organizational goals, the knowledge-based view promotes the sharingof knowledge. From the supply chain management point of view this sharing is amongst the various actors in the supply chain. The agency theory was built on the foundation of the traditional view of organization that views organizations as black boxes of operations, where the "relationship betweenperformance and incentives" was overlooked (Shook, Adams, Ketchen and Craighead 2009). Thecontemporary view of agency theory lays forward the practice of delegation of responsibilities andoperation, through an open system view towards the environment.Agency theory has been applied to various activities associated supply chain management including, outsourcing and supply chain collaboration..

Porter developed the five-forces model that defines the attractiveness and profitability of an industry or market. 


\section{International Journal of Science and Research (IJSR) \\ ISSN (Online): 2319-7064}

Index Copernicus Value (2013): 6.14 | Impact Factor (2014): 5.611

These forces are; bargaining power of customers, bargaining power of suppliers,intensity of existing competitive rivalry, threat of new entrants and threat of substitute products. This framework is generally used for the analysis of industry and development of business strategy. According to this model, the objective of corporate strategy should be to manage these competitive forces in a way that improves the position of the organization and achieve competitive advantage.Porter (1980) also identified the competitive generic strategies that can be applied after successful competitive analysis that is, cost leadership and differentiation strategy, and focus strategy.

\section{Empirical Review}

Supply chain management has received increasing attention from both practitioners and academia. Effectivelymanaging the flow of materials from supply sources to the ultimate customerrepresents a major challenge for today's managers.Prior research has identified three major supply chain strategies: lean, agile, andlean \& agile (hybrid) strategies (Yusuf, Gunasekaran, Adeleye, \&Sivayoganathan, 2004). Several research studies have shown that a lean strategy produces higher levels of quality and productivity and better customer responsiveness. The impact on lean strategy is mostly based on empirical evidence that it improves the company's competitiveness. The impact of lean thinking as a strategy is important not only in manufacturing but also for the entire organization. This focus provides support for the argument that it is the collective responsibility of all managers to continually strive for improvement within and between organizations. Lambert (1998) suggests that the structure of activities/processes within and between companies is crucial for achieving superior competitiveness and profitability.

While lean management emphasizes the pursuit of process efficiency, generating the greatest outcome from the least input through the minimization of wastes, agility refers to effective flexible accommodation of unique customer demands (Christopher 2000). The key to providing agile response is flexibility throughout the supply chain.Response based supply chains are always characterized as short, with few or no intermediaries (Christopher and Towill 2000). Based on flexibility and the response to customer, agility alsoincludes cost reduction, high quality of products and the delivery conditions and service. Collaboration with multiple companies, different relationships with business partners orto outsource the work to a third party may be a solution (Lee, 2010).Researchers in recent years have suggested that the two approaches need not necessarily represent opposing views; rather they may be merged in a variety of ways to create leagile approach strategies.
Leagile is the combination of the lean and agile paradigms within a total supply chain strategy by positioning the decoupling point so as to best suit the need for responding to a volatile demand downstream yet providing level scheduling upstream from the marketplace.' Christopher and Towill (2002) conceived three distinct hybrids. The first hybrid approach embraces the Pareto (80/20) rule, recognizing that $80 \%$ of company revenue is generated from $20 \%$ of the company's products. They suggested that the first moving products that make up the dominant $20 \%$ of the product line can be produced in a lean, make to stock manner given that the demand is relatively stable for these items and that efficient replenishment is the appropriate objective. The remaining $80 \%$ should be produced in an agile less anticipatory manner employing make to order production to generate supply of those items ordered when they are needed. Many companies engage in leagile supply, manufacturing and logistics to support seasonal demands Christopher \&Towill (2002).Mason-Jones et al. (2000) propose a leagile model where the lean and agile systems operate at different points in a manufacturing supply chain.

One of the organizations' major concerns is to care about customers' needs and wants and transform such needs and wants into targeted aptitudes or areas called "competitive dimensions". These dimensions that organizations focus on and show great interest in, while providing services and products so as to meet market demand, can help organizations achieve competitive advantage. These competitive dimensions are four and include cost, quality, time and flexibility.In general, most organizations choose to cut total cost by stripping fixed costs and applying continuous control on raw materials, reducing employee compensation rates, and by achieving higher levels of productivity.

\section{Conceptual Framework}

Though various studies have been undertaken examining the link between supply chain management practices, little attention seem to have been directed to understanding potential relationship between supply chain strategies and organizational outcomes. Still such a relationship could be examined with recognition of existence of other factors that could influence such relationships. For purposes of this study, the independent variables are supply chain strategies, while the dependent variable is competitive advantage. Government policies is picked as one of those variables that could influence the direction and extent of the perceived relationship. 
International Journal of Science and Research (IJSR)

ISSN (Online): 2319-7064

Index Copernicus Value (2013): 6.14 | Impact Factor (2014): 5.611

Independent variables

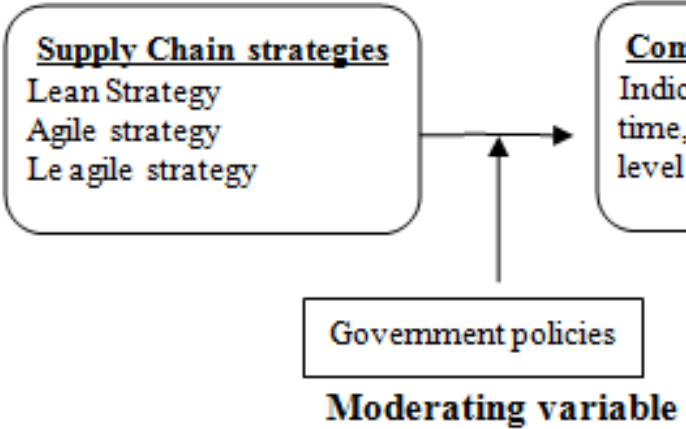

\section{Dependent variables}

Competitive advantage

Indicators - cost, lead-

me, quality and service

evel

Figure 1: Supply chain strategies, government policies and competitive advantage

\section{Research Methodology}

The study adopted the descriptive research approach.Descriptive research is a scientific method of investigation where data is collected and analyzed in order to describe the current conditions, terms or relationships concerning a problem (Mugenda and Mugenda,2003). The design was suitable because it is concerned with describing the influence of supply chain strategies on achievement of competitive advantage in seed manufacturing companies in Nairobi, Kenya.

The target respondents of this study wereforty respondents from twentyseed manufacturing companies in Nairobi County. The main target respondents comprised oftop supply chain managers and strategic planning managers. These managers were targeted because they are considered to have an overall understanding of supply chain strategies and competitive advantage of the firm.

Primary data was collected using structured questionnaires with both close-ended andopen-ended questions. Primary data will be collected fromthe targetrespondents. Secondary data was gathered from library material, supply chain journals and reports, media publications and various internet search engines covering the supply chain management and competitive advantage.Secondary data was used in introduction and literature reviews parts of this paper. This research study adopted contentvalidity that was determined through seeking opinions of experts in the field of study especially in the department of supply chain in seed crop supply manufacturing companies in Nairobi Kenya.Reliability of the research instrument was enhanced through coefficient correlation method, using Cronbach'sCoefficient alpha $(\alpha)$.The study objectives wereanalysed using both descriptive and inferential statistics to describe and examine the relationship between the variablesof interest, with the aid of the computer software the statistical package for social sciences (SPSS).The purpose of descriptive statistics is to meaningfully describe a distribution of scores or measurements, using a few indices. Inferential statistics involved use of correlation analysis.

\section{Findings and Discussion}

Respondent companies were categorized into large, medium and small sized companies. Majority of the respondentcompanies were medium sized (42.1\%). The findings are summarized in Table 1 below.

Table 1: Respondent companies categorized based on size

\begin{tabular}{|c|c|c|}
\hline Size of the company & Frequency & Percent \\
\hline Large size & 13 & 34.2 \\
\hline Medium sized company & 16 & 42.1 \\
\hline Small sized company & 9 & 23.7 \\
\hline Total & 38 & 100 \\
\hline
\end{tabular}

\section{Descriptive Statistics}

\section{Supply chain strategies pursued by seed manufacturing companies Nairobi}

The study sought to explore the supply chain strategies practiced in the seed manufacturing company. The respondents were asked to indicatethe extent to whichvarious appropriate strategies (lean, agile and leagile) are employed in their respective companies. A five-point likert scale anchored from $1=$ very small extent; $2=$ small extent; $3=$ moderate; $4=$ large extent, $5=$ Very large extent was used.The findings are summarized in Table 2 below.

Table 2: Supply Chain strategies employed

\begin{tabular}{|c|c|c|c|c|c|c|}
\hline \multirow{2}{*}{$\begin{array}{c}\text { Supply } \\
\text { Chain } \\
\text { Strategy }\end{array}$} & $\begin{array}{c}\text { Very small } \\
\text { extent }\end{array}$ & $\begin{array}{c}\text { small } \\
\text { extent }\end{array}$ & Moderate & $\begin{array}{c}\text { Large } \\
\text { extent }\end{array}$ & $\begin{array}{c}\text { very } \\
\text { large } \\
\text { extent }\end{array}$ & \multirow{2}{*}{ Mean } \\
\cline { 2 - 6 } & 1 & 2 & 3 & 4 & 5 & \\
\hline Lean & $1(2.6)$ & $3(7.9)$ & $6(15.8)$ & $11(28.9)$ & $17(44.7)$ & 4.05 \\
\hline Agile & $2(5.3)$ & $3(7.9)$ & $7(18.4)$ & $9(23.7)$ & $17(44.7)$ & 3.95 \\
\hline Le agile & $2(5.3)$ & $7(18.4)$ & $6(15.8)$ & $13(34.2)$ & $10(26.3)$ & 3.56 \\
\hline
\end{tabular}

The findings in Table 2 above established that the lean strategy was widely employed across the seed manufacturing companies at a mean of 4.05. This was followed by the agile strategy at a mean of 3.95 and the le agile strategy was employed with the organizations at a mean of 3.56. this finding concurs with Fisher (1997) and Christopher and Towill (2000) arguments that supply chain strategies must match with product characteristics, competitive strategies, and the environment in order for them to be effective.

\section{Supply chain strategies and Competitive Advantage}

An attempt was made to engage respondents on the perceived relationship between the variables of interest (each of the supply chain strategies and competitive advantage). The metrics of competitive advantage dimensions of cost, lead time, quality and service level were 


\section{International Journal of Science and Research (IJSR) \\ ISSN (Online): 2319-7064}

Index Copernicus Value (2013): 6.14 | Impact Factor (2014): 5.611

utilized. The respondents were asked to indicatethe extent to which each of the supply chain strategies (lean, agile and leagile) have influenced the realization of competitive advantage on each of the competitive advantage metrics. A five-point Likert scale anchored from $1=$ very small extent; $2=$ small extent; $3=$ moderate; $4=$ large extent, $5=$ Very large extent was used. The mean score ratings are presented in Table 3 below.

Table 3: Supply chain strategies and competitive advantage

\begin{tabular}{|c|c|c|c|}
\hline \multirow{2}{*}{$\begin{array}{c}\text { Competitive } \\
\text { advantage } \\
\text { dimensions }\end{array}$} & \multicolumn{3}{|c|}{$\begin{array}{c}\text { Mean rating on each competitive advantage } \\
\text { dimensions }\end{array}$} \\
\cline { 2 - 4 } & \multicolumn{3}{|c|}{ Supply chain strategies } \\
\hline & Lean strategy & Agile strategy & Leagile strategy \\
\hline Cost & 4.16 & 3.34 & 4.00 \\
Lead time & 4.16 & 4.03 & 4.16 \\
Quality & 3.87 & 3.53 & 3.34 \\
Service Level & 3.97 & 3.53 & 4.16 \\
\hline
\end{tabular}

From the results in Table 3, it can be deduced that each of the supply chain strategies influences the achievement of competitive advantage on all the competitive advantage metrics.

Lean strategy influences reduction of costs to a large extent as reflected by the mean score of 4.16 out of a maximum of 5 score. The findings also indicate that lead time, the ability of the manufacturing firm to execute a particular job from the date of ordering to the date of delivery quickly and as soon as the order is placedwas reduced at a mean of 4.16 , implying that similarly lean strategy influences attainment of competitive advantage to a large extent. Further, lean strategy influenced level of quality achieved (the standard of the finished product) to a moderate extent with a mean rating of 3.87. Service level was also high with lean strategy as indicated by a mean rating of 3.97. These findings imply that use of lean strategy hadinfluenced competitive advantage in seed manufacturing companies in Nairobi County, Kenya.

Findings also reveal that the agile supply chain strategy influences competitive advantage as indicated by mean scores on the metrics of competitive advantage (see table 3 above). The mean rating on cost reduction, lead-time, quality level and service level is 3.34, 4.03, 3.53 and 3.53 respectively. This implies that the agile strategy does not greatly influence cost minimization, but it does influence to a great extent the ability of the manufacturing firm to execute a particular job from the date of ordering to the date of delivery quickly. Agile strategy influenced quality and service level outcomes to a moderate extent.These findings imply that use of agile strategy had influenced competitive advantage in seed manufacturing companies in Nairobi County, Kenya.

From the findings presented in table 3 above, it can be deduced that the Le agile supply chain strategy have influenced competitive advantage. This is indicated by the ratings on each of the metrics of competitive advantage. The mean score ratings out of a maximum of 5 points is 4.0 , $4.16,3.34$ and 4.16 on dimensions cost, lead-time, quality and service level. This finding implies that minimization of expenses is manifested in company operations to a large extent, le agile strategy influences lead time attained to a large extent, le agile strategy influences service level as to a large extent and Le agile strategy influenced quality outcomes to a moderate extent.These findings imply that use of Le agile strategy had influenced competitive advantage in seed manufacturing companies in Nairobi County, Kenya.

\section{The moderating effect of government policies in the relationship between supply chain strategies and competitive advantage}

The study sought to establishthe moderating effects of government policies on the relationship between supply chain strategies and attainment of competitive advantage. Majority of the respondents $55.26 \%$ felt that the government had an influence on the effectiveness of supply chain strategies towards the realization of competitive advantage. The findings are summarized in Table 4 below.

Table 4: The moderating effects of Government policies

\begin{tabular}{|c|c|c|}
\hline & Frequency & Percent \\
\hline Yes & 21 & 55.26 \\
\hline No & 17 & 44.74 \\
\hline Total & 38 & 100 \\
\hline
\end{tabular}

The government policies play an integral role in the success of any organizations. They can influence or deter the strategies of an organization from translating into the planned outcomes. Respondents were asked to identify policies they felt affects the effectiveness of supply chain strategies. Majority of the respondents indicated that the policies that had an influence include Government Seed Regulation, ISO Certifications, Licensing, Market Restriction; Stream lined policies, Technology and trade unions.

\section{Inferential statistics}

Correlation analysis was employed to measure the nature and strength of relationship between supply chain strategies and achievement of competitive advantage. Hence Pearson's product moment coefficient was computed. The correlation coefficient results are summarized and presented in table 5 below.On the other hand, positive correlation implies that the variables are moving in the same positive direction. The correlation analysis was used to determine whether lean strategy influenced competitive advantage in seed manufacturing companies.

Table 5: Correlation analysis results: supply chain strategies and competitive advantage

\begin{tabular}{|c|c|c|c|c|c|}
\hline \multicolumn{2}{|c|}{ Strategy } & Cost & $\begin{array}{c}\text { Lead } \\
\text { Time }\end{array}$ & Quality & $\begin{array}{c}\text { Service } \\
\text { Level }\end{array}$ \\
\hline Lean Strategy & Pearson & .750 & .626 & .732 & .675 \\
Agile strategy & Correlation & .810 & .671 & .712 & .522 \\
Leagile strategy & & .582 & .522 & .589 & .568 \\
\cline { 2 - 6 } & Sig. (2-tailed) & .000 & .000 & .000 & .000 \\
\cline { 2 - 6 } & $\mathrm{N}$ & 38 & 38 & 38 & 38 \\
\hline
\end{tabular}

Correlation significant at the 0.05 level (2-tailed)

Correlation results show that a strong relationship existsbetween the supply chain strategies and all metrics of competitive advantage. On lean strategy, the relationship was strongest with the dimension of cost $(r=0.750)$ and quality $(r=0.732)$. This indicates that organizations that employed lean strategy had competitive advantage in terms of cost and quality.The lean strategy was also correlated

\section{Volume 5 Issue 1, January 2016}




\section{International Journal of Science and Research (IJSR) \\ ISSN (Online): 2319-7064}

Index Copernicus Value (2013): 6.14 | Impact Factor (2014): 5.611

with lead time $(r=0.626)$ and service level $(r=0.675)$. These correlation analysis results also suggest that the relationship is positive implying lean strategy influenced competitive advantage.

The correlation analysis results on the relationship between agile strategy and competitive advantage reveals that the strongest correlation was withthe aspects of cost $(\mathrm{r}=0.810)$ and quality $(\mathrm{r}=0.712)$. This indicates that organizations that employed agile strategy had competitive advantage in terms of cost and quality. The agile strategy was also correlated with lead time $(r=0.671)$ and service level $(r=0.522)$. The correlation coefficients suggest that the relationship is positive implying agile strategy influenced competitive advantage.

A correlation analysis to determine whether the Le agile strategy influenced competitive advantage in seed manufacturing companies was also conducted. Findingsshow that a significant relationship exists between the le agile strategy and the aspects of competitive advantage - cost $(\mathrm{r}=0.582)$ and quality $(\mathrm{r}=0.589)$. This was followed by service level with $(\mathrm{r}=0.568)$ and finally lead time with $(\mathrm{r}=0.522)$. Pearson's product moment coefficient also suggests that the relationship is positive implying leagile strategy influenced competitive advantage.

\section{Conclusions and Recommendations}

Based on the findings, the study concludes that either of the supply chain strategies, that is lean, agile or leagile were been employed by the seed manufacturing companies in Nairobi.The study further concludes that there is a significant influence of supply chain strategies on the achievement of a firm's competitive advantage. Indeed there is a strong relationship between supply chain strategies and achievement of a firm's competitive advantage dimensions of cost, lead time, service level and quality. This relationship is significant. This may be because of the nature and dynamism of the agribusiness environment therefore the need to stay abreast with it. The strategies correlated very positive with all the competitive advantage metrics. It is further noted that the government policies moderates the postulated relationship between these two variables.

Based on the findings, discussions and conclusions of this research, the study recommends that firms should develop competitive advantage capabilities that cannot be imitated by other competitors in the area of creativity and innovations which will ensure they remain competitive in the industry.Management need to take a keen interest specifically on supply chain strategies. This is so because these strategies are likely to determine the level of competitiveness that a company can enjoy (cost management or differentiation in quality and service). The study findings strongly confirm this. Thus agribusiness companies need to adopt and implement good supply chain strategies to have higher competitive advantage. More so, this will ensure that interests of the firm are served as well as sustaining customer and maintaining customer satisfaction. The government should provide a more enabling environment that would encourage agribusiness firms to achieve their objectives.
The study covered the areas in the main objectives which were not exhaustive in determining the influence of supply chain strategies in achievement of competitive advantage.Researchers could make an attempt to establish the reasons behind thefailure of supply chain strategies implementation hence establish long termsolutions. There are other variables that could be brought into play to build more elaborate model to aid the examination of the relationship between supply chain strategies and competitive advantage. For instance the strategy formulation process and the prerequisite for effectiveness of these strategies could be given room in this model.

\section{References}

[1] Bryceson, K. P \&Smith, C. S (2008), “Abstraction and Modelling of Agri-Food Chains as Complex Decision Making Systems", Proceedings of the EAAE Conference on 'System Dynamics and Innovation in Food Networks' February, pp. 18-22, Innsbruck-Igls, Austria.

[2] Christopher M (2005), Logistics and Supply Chain Management, Prentice Hall, London

[3] Chopra, S, \&Meindl, P. (2007). Supply Chain Management: Strategy, Planning, \& Operation. (3th ed) NJ: Prentice-Hall. Inc.

[4] Christopher,M., \&Towill, D. R. (2000). Supply chain migration from lean and functional to agile and customized. Supply Chain Management: An InternationalJournal, 5(4), 206-213.

[5] Christopher,M.,\&Towill, D. (2002 ).The Supply Chain Strategy Conundrum: to be lean or agile or to be lean and agile? International Journal of Logistics: Research and Applications,

[6] Grant, R.M., (1991), the Resource-Based Theory of Competitive Advantage: Implications for Strategy Formulation, California Management Review, Vol. 33(3), pp. 114-135.

[7] Hamel, G., DOZ, Y. L. \&Prahalad, C. K. (2002). Collaborate with your competitors and win. Harvard Business Review on strategic alliances. Boston: Harvard Business School Publishing.

[8] Lambert. M. \& Cooper, M. C. (2000). Issues in supply chain management. Industrial Marketing Management, 29(1), 65-83.

[9] Lee L., H. (2010), don't tweak your supply chain rethink it end to end. Harvard Business Review

[10] Martin C.,\& John G., (2005)."Supply chain cost management and value-based pricing," Industrial Marketing Management 34, 115-121.

[11] Mason J., Naylor, B. \&Towill, D (2000) Lean, agile or leagile? Matching your supply chain to the market place. International Journal of Production Research, 17

[12] Morash E. A. and Lynch D. F. (2002) Public Policy and Global Supply Chain Capabilities and Performance: A Resource-Based View, Journal of International Marketing, 10(1), pp: 25-51.

[13] Ministry of Agriculture. (2010). Strengthening the viability of common interest groups (CIGS) for agribusiness development. Retrieved From,www.nafis.go.ke/wpcontent/uploads/2011/10/cig_report1.pdf 


\section{International Journal of Science and Research (IJSR) \\ ISSN (Online): 2319-7064}

Index Copernicus Value (2013): 6.14 | Impact Factor (2014): 5.611

[14] Mugenda, M.,\&Mugenda, G. (2003). Quantitative and Qualitative Approaches. Research Methods. Nairobi, Kenya.

[15] Porter, M. (1980), Competitive Strategy: Techniques for Analyzing Industries and Competitors, Free Press, New York.

[16] Shook C. L., Adams G. L., Ketchen D. J. \&Craighead C. W. (2009), Towards a "theoretical toolbox" for strategic sourcing. Supply Chain Management: $A n$ International Journal, 14(1), pp: 3-10.

[17] Wu F., Yeniyurt S., Kim D. \&Cavusgil S. T. (2005). The impact of information technology on supply chain capabilities and firm performance: A resource-based view, Industrial Marketing Management, 35(4), pp: 493-504.

[18]Xiao F.D., Stephen C.H., \&Jin L. Z., (2009),"Procurement of agricultural products using the CPFR approach", Supply Chain Management: An International Journal, Vol. 14 Iss: 4 pp. 253 - 258.

[19] Yusuf, Y. Y., Gunasekaran, A., Adeleye, E. O., \&Sivayoganathan, K. (2004). Agile supply chain capabilities: Determinants of competitive objectives. EuropeanJournal of Operational Research, 159(2), 379-392.

\section{Author Profile}

Dr. Robert Arasa is currently a Senior Lecturer and Director of Graduate Business School, The Catholic University of Eastern Africa, Kenya. Before joining the academia Dr. Arasa had worked for than 10 years in the corporate sector; having worked for National Health Scheme - Kenya (heading Research and Business Development dockets), Institute of Policy Analysis and Research (where he is currently an Research Associate). Dr. Arasa is also involved in consultancy services in the areas of strategy, supply chain management and management trainings. He is enlisted by reputable international journals as a reviewer and has also written and published in the fields of strategy, supply chain management and management. Dr. Arasa hold a PhD in Strategic Management, MBA from University of Nairobi, Kenya.

Ms Rose Mwaura is a supply chain professional at Monsanto Kenya Limited, within the Agribusiness sector, based in Nairobi. Rose has a Bachelor's degree in Marketing from Kenya Methodist University and aMasters of Business Administration from The Catholic University of Eastern Africa. Her interest in research is in the area of supply chain management.

Dr. Tomas Ngui is a lecturer and deputy Head of Department of Marketing and Management, Faculty of Commerce and MBA coordinator, The Catholic University of Eastern Africa. He holds a $\mathrm{PhD}$ in Human Resource Management from Jomo Kenyatta University of Agriculture and Technology, Kenya. He has published widely in the field of management. 